\title{
Strategi Optimalisasi Peran BUMDEs dalam Mendorong Pemerataan Ekonomi Desa
}

\author{
Eva Yunita*
}

Prodi Ekonomi Pembangunan, Fakultas Ekonomi dan Bisnis, Universitas Islam Bandung, Indonesia.

*evaaynt14@gmail.com

\begin{abstract}
This study tries to describe the strategy of optimizing the role of BUMDes in promoting economic equity in Margaasih Village, Bandung Regency, West Java. In Law No. 6 of 2014 it is stated that in order to improve the welfare of the people in the equitable distribution of the village economy, it is necessary to form a Village Owned Enterprise (BUMDes). Margaasih Village is a developed village, although it has a developed village, Margaasih Village does not yet have an equal distribution of welfare, this is indicated by the existence of poverty. Poverty in $2017-2020$ which states that there is no change in Margaasih Village. Therefore we need a strategy that can optimize the role of BUMDes so that there is equity in Margaasih Village. The research method used to formulate the optimization strategy is using qualitative analysis using primary sources, namely direct interviews, using the SOAR analysis method. Based on the results of SOAR analysis, the optimal strategy is obtained, namely S (Strengths) and R (Result), Strategy to 1 . increase the productivity of BIMA BUMDes management services for underprivileged communities; 2. The BIMA BUMDes management must be more active in promoting activities within the BUMDes through outreach to residents and also through available websites.
\end{abstract}

Keywords: Margaasih Village, BUMDes, Optimization Strategy, SOAR..

\begin{abstract}
Abstrak. Penelitian ini mencoba menggambarkan strategi optimalisasi peran BUMDes dalam mendorong pemerataan ekonomi Desa Margaasih, Kabupaten Bandung, Jawa Barat. Didalam Undang - Undang No. 6 Tahun 2014 dinyatakan bahwa untuk meningkatkan kesejahteraan rakyat dalam pemerataan ekonomi desa maka diperlukan pembentukan Badan Usaha Milik Desa (BUMDes). Desa Margaasih termasuk desa maju, walaupun memiliki desa maju, Desa Margaasih ini belum adanya pemerataan kesejahteraan, hal ini ditunjukan dengan adanya kemiskinan. Kemiskinan di tahun 2017 - 2020 yang menyatakan bahwa tidak adanya perubahan di dalam Desa Margaasih. Oleh karena itu diperlukan sebuah strategi yang dapat mengoptimalkan peran BUMDes sehingga terjadi pemerataan di Desa Margaasih. Metode penelitian yang digunakan untuk merumuskan strategi optimalisasi tersebut yakni menggunakan analisis kualitatif dengan menggunakan sumber primer yakni melakukan wawancara langsung, dengan alat metode analisis SOAR. Berdasarkan hasil analisis SOAR maka disini didapatkan strategi yang optimal yakni S (Strengths) dan R (Result), Strategi ini menekankan kepada 1. Meningkatkan produktivitas pelayanan manajemen BUMDes BIMA untuk masyarakat yang kurang mampu; 2. Pengurus BUMDes BIMA harus lebih aktif dalam mempromosikan kegiatan yang berada di dalam BUMDes melalui penyuluhan terhadap warga dan juga melalui website yang tersedia.
\end{abstract}

Kata Kunci: Desa Margaasih, BUMDes, Strategi Optimalisasi, SOAR. 


\section{A. Pendahuluan}

Pembangunan desa merupakan komitmen besar Bangsa Indonesia yang tertuang dalam Undang - Undang No. 6 Tahun 2014. Pembangunan desa dalam undang-undang tersebut merupakan kewenangan desa di bidang penyelenggaraan pemerintahan desa, pelaksanaan pembangunan desa dan pembinaan kemasyarakatan desa. Salah satu ukuran yang dibuat Kementerian Desa Pembangunan Daerah Tertinggal dan Transmigrasi (Kemendes PDTT) untuk melihat sejauh mana pembangunan yang sudah dilakukan oleh desa-desa di Indonesia yakni dengan dibuatnya indeks desa membangun (IDM).

Kabupaten Bandung pada tahun 2020 memiliki jumlah desa maju terbanyak dibandingkan Kabupaten lainnya dengan jumlah 150 desa atau 9,11 persen dari jumlah total desa yang berada di Provinsi Jawa Barat. Mendominasinya Kabupaten Bandung dalam klasifikasi desa maju juga tercatat bahwa Kabupaten Bandung tidak memiliki jumlah desa sangat tertinggal dan desa tertinggal. Dalam hal ini merupakan pencapaian terbesar dari pembangunan desa di Kabupaten Bandung, untuk menunjang hal tersebut diperlukannya peran BUMDes. Kabupaten Bandung memiliki jumlah 270 BUMDes dengan peringkat ketiga setelah Kabupaten Sukabumi 381 BUMDes dan Kabupaten Bogor 280 BUMDes. Dengan demikian banyaknya jumlah BUMDes yang berada di wilayah Kabupaten Bandung diharapkan mampu menjadikan status desa maju lebih bertambah.

Salah satu Desa di Kab. Bandung yang berstatus maju dan memiliki BUMDes yang aktif dengan aset sebesar 535.199.585 Rupiah dan omset rata-rata pertahun sampai 1.267.924.319 Rupiah yakni Desa Margaasih. BUMDes yang ada di margaasih ini Bernama BUMDes "Bina Margaasih" (BIMA). Status BUMDes Desa Margaasih yakni BUMDes Berkembang, dimana BUMDes ini sudah termasuk BUMDes yang bagus. Hal ini karena dari keempat status BUMDes yakni dasar, tumbuh, berkembang dan maju, BUMDES BIMa masuk ke peringkat status kedua. Walaupun BUMDes BIMA termasuk bumdes yang bagus, namun ternyata pemerataan kesejahteraan ekonomi masyarakat Desa Margaasih belum merata. Hal ini ditunjukkan dengan tidak adanya perubahan angka kemiskinan di Desa Margaasih. Informasi ini diperoleh berdasarkan hasil wawancara dengan (Pusat Kesejahteraan Sosial) PUSKESOS Desa Margaasih pada tahun 2021. Hasil wawancara menunjukkan bahwa masyarakat miskin di Desa Margaasih dari tahun 2017 - 2020 tidak mengalami perubahan atau jumlahnya tetap yakni sebanyak 2.585 rumah tangga miskin. Jika melihat besaran Omzet dan Asset yang diperoleh BUMDes BIMA, seharusnya BUMDES BIMA dapat membantu mengatasi permasalahan kemiskinan di Desa Margaasih.

\section{B. Metodologi Penelitian}

Metode dalam penelitian ini yakni menggunakan metode penelitian deskriptif dengan pendekatan kualitatif. "Metode penelitian deskriptif yaitu suatu metode yang digunakan untuk menggambarkan atau memecahkan masalah secara sistematis, faktual, dan akurat mengenai fakta-fakta dan sifat-sifat populasi atau daerah tertentu" (Kuncoro, 2001). Metode analisis yang digunakan ialah metode analisis SOAR (Strengths, Opportunities, Aspirations, Results). Stavros, Cooperrider, dan Kelly (2003), menawarkan konsep SOAR sebagai alternatif terhadap analisis SWOT.

\section{Hasil Penelitian dan Pembahasan \\ Matriks Internal Factor Evalution (IFE)}

Merupakan sebuah alat formulasi strategi yang digunakan untuk meringkas dan mengevaluasi kekuatan dan aspirasi dan memberikan dasar untuk mengidentifikasi hubungan antara area-area tersebut (David, 2006).

Tabel 1. Strengths (Civil Society)

\begin{tabular}{|l|c|c|c|c|}
\hline No & Kekuatan/ Strengths & Bobot & Rating & Skor \\
\hline 1. & BUMDes BIMA memiliki kegiatan yang sangat & 0.26 & 4.4 & 1.13 \\
\hline
\end{tabular}




\begin{tabular}{|c|c|c|c|c|}
\hline No & Kekuatan/Strengths & \multirow[t]{2}{*}{ Bobot } & \multirow[t]{2}{*}{ Rating } & \multirow[t]{2}{*}{ Skor } \\
\hline & $\begin{array}{l}\text { mementingkan kesejahteraan desa, seperti } \\
\text { kegiatan simpan pinjam atau pengelolaan } \\
\text { sampah. }\end{array}$ & & & \\
\hline 2. & $\begin{array}{l}\text { BUMDes BIMA membuat program yang dapat } \\
\text { mengembangkan potensi desa, seperti kerajinan } \\
\text { tangan warga membuat dompet dan mengelola } \\
\text { limbah plastik. }\end{array}$ & 0.21 & 4.2 & 0.88 \\
\hline 3. & $\begin{array}{l}\text { BUMDes BIMA memberikan pelatihan kepada } \\
\text { masyarakat untuk menambah pengetahuan dan } \\
\text { keterampilan anggota dalam berbagai bidang } \\
\text { misalnya pelatihan berwirausaha. }\end{array}$ & 0.08 & 4.1 & 0.34 \\
\hline 4. & $\begin{array}{l}\text { BUMDes BIMA pada waktu - waktu tertentu } \\
\text { memberikan penyuluhan tentang berwirausaha } \\
\text { kepada masyarakat. }\end{array}$ & 0.11 & 4.1 & 0.47 \\
\hline 5. & $\begin{array}{l}\text { Sebelum membuat dan menjalankan program } \\
\text { baru, BUMDes BIMA meminta persetujuan } \\
\text { masyarakat desa. }\end{array}$ & 0.20 & 3.9 & 0.79 \\
\hline 6. & $\begin{array}{l}\text { BUMDes BIMA menerima masukan dari } \\
\text { masyarakat untuk kemajuan bersama. }\end{array}$ & 0.14 & 4.4 & 0.61 \\
\hline & Nilai Total Strength & $\mathbf{1 . 0 0}$ & & 4.21 \\
\hline
\end{tabular}

Sumber: Olahan Peneliti, 2021

Tabel 2. Aspirations (Social Value)

\begin{tabular}{|c|l|c|c|c|}
\hline No & \multicolumn{1}{|c|}{ Harapan/ Aspirations } & Bobot & Rating & Skor \\
\hline 1. & $\begin{array}{l}\text { Adanya regulasi pengurus Badan Usaha Milik } \\
\text { Desa (BUMDes) per tahunnya. }\end{array}$ & 0.15 & 4.1 & 0.62 \\
\hline 2. & $\begin{array}{l}\text { Masyarakat dan anggota BUMDes mengetahui } \\
\text { tugas dan fungsi BUMDes . }\end{array}$ & 0.05 & 4.0 & 0.22 \\
\hline 3. & $\begin{array}{l}\text { BUMDes BIMA berinisiatif untuk membantu } \\
\text { menawarkan produk usaha anda ke pasar. }\end{array}$ & 0.08 & 4.2 & 0.32 \\
\hline 4. & $\begin{array}{l}\text { BUMDes BIMA aktif memanfaatkan potensi } \\
\text { desa (sumber daya alam dan sumber daya } \\
\text { manusia) serta mengembangkannya untuk } \\
\text { kesejahteraan desa. }\end{array}$ & 0.10 & 4.1 & 0.40 \\
\hline 5. & $\begin{array}{l}\text { BUMDes BIMA menggunakan teknologi yang } \\
\text { lebih modern dalam pengelolaan air maupun } \\
\text { sampah. }\end{array}$ & 0.12 & 4.1 & 0.49 \\
\hline 6. & $\begin{array}{l}\text { BUMDes BIMA berdiri dengan tujuan untuk } \\
\text { memperbaiki kondisi perekonomian masyarakat } \\
\text { melalui kegiatan simpan pinjam, pengelolaan }\end{array}$ & 0.17 & 4.2 & 0.70 \\
\hline
\end{tabular}




\begin{tabular}{|c|l|c|c|c|}
\hline No & \multicolumn{1}{|c|}{ Harapan/ Aspirations } & Bobot & Rating & Skor \\
\hline & sampah dan usaha lainnya. & & 0.1 \\
\hline 7. & $\begin{array}{l}\text { Melalui pengelolaan dan pemanfaatan sumber } \\
\text { daya yang baik dan profesional BUMDes } \\
\text { BIMA telah mampu meningkatkan PAD } \\
\text { (Pendapatan Asli Desa). }\end{array}$ & 0.15 & 4.3 & 0.78 \\
\hline 8. & $\begin{array}{l}\text { Usaha simpan pinjam dan pengelolaan sampah } \\
\text { yang dijalankan oleh BUMDes BIMA } \\
\text { membantu perekonomian dan mensejahterakan } \\
\text { masyarakat desa. }\end{array}$ & 0.18 & $\mathbf{4 . 1 5}$ \\
\hline Nilai Total Aspirations & $\mathbf{1 . 0 0}$ & $\mathbf{8 . 3 6}$ \\
\hline
\end{tabular}

Sumber: Olahan Peneliti, 2021

\section{Matriks Eksternal Factor Evalution (EFE)}

Digunakan untuk mengetahui faktor - faktor eksternal suatu organisasi atau perusahaan yang berkaitan dengan peluang dan hasil yang dianggap penting. Data eksternal dikumpulkan untuk menganalisis hal-hal menyangkut persoalan ekonomi, sosial, budaya, demografi, lingkungan, politik, pemerintahan, hukum, teknologi, dan persaingan (David, 2006).

Tabel 3. Opportunities (Innovation)

\begin{tabular}{|c|l|c|c|c|}
\hline No & \multicolumn{1}{|c|}{ Peluang/ Opportunities } & Bobot & Rating & Skor \\
\hline 1. & $\begin{array}{l}\text { BUMDes BIMA dapat lebih mudah untuk } \\
\text { mendapatkan modal mengembangkan usaha. }\end{array}$ & 0.18 & 4.2 & 0.73 \\
\hline 2. & $\begin{array}{l}\text { BUMDes BIMA bekerjasama dengan mitra } \\
\text { eksternal untuk menghasilkan kesejahteraan } \\
\text { masyarakat desa }\end{array}$ & 0.15 & 4.3 & 0.63 \\
\hline 3. & $\begin{array}{l}\text { Dengan adanya kerjasama dengan BUMDes } \\
\text { dengan shopee mampu mendukung UMKM } \\
\text { melalui peningkatan literasi digital }\end{array}$ & 0.11 & 4.1 & 0.45 \\
\hline 4. & $\begin{array}{l}\text { Dengan adanya BUMDes BIMA dapat } \\
\text { menyerap tenaga kerja dari masyarakat desa. }\end{array}$ & 0.10 & 4.2 & 0.44 \\
\hline 5. & $\begin{array}{l}\text { Anda ataupun anggota keluarga anda bekerja } \\
\text { sebagai pengurus BUMDes maupun karyawan } \\
\text { dari usaha yang dijalankan oleh BUMDes } \\
\text { BIMA. }\end{array}$ & 0.18 & 3.9 & 0.69 \\
\hline 6. & $\begin{array}{l}\text { Usaha yang dikembangkan oleh BUMDes } \\
\text { BIMA terbentuk atas inisiatif masyarakat. }\end{array}$ & 0.11 & 3.8 & 0.42 \\
\hline 7. & $\begin{array}{l}\text { Anda ikut berpartisipasi aktif dalam } \\
\text { mengembangkan BUMDes BIMA dengan } \\
\text { terlibat sebagai pegawai BUMDes maupun }\end{array}$ & 0.18 & 3.8 & 0.68 \\
\hline
\end{tabular}




\begin{tabular}{|c|c|c|c|c|}
\hline No & Peluang/ Opportunities & Bobot & Rating & Skor \\
\hline & $\begin{array}{l}\text { sebagai anggota yang memanfaatkan bantuan } \\
\text { modal BUMDes untuk berwirausaha. }\end{array}$ & & & \\
\hline Nilai Total & $\mathbf{1 . 0 0}$ & & $\mathbf{4 . 0 4}$ \\
\hline
\end{tabular}

Tabel 4. Results (Economic Activity)

\begin{tabular}{|c|c|c|c|c|}
\hline No & Harapan/ Results & Bobot & Rating & Skor \\
\hline 1. & $\begin{array}{l}\text { BUMDes BIMA dalam melakukan pelayanan } \\
\text { tidak memandang golongan, suku dan agama. }\end{array}$ & 0.11 & 4.3 & 0.49 \\
\hline 2. & $\begin{array}{l}\text { BUMDes BIMA memiliki website tersendiri } \\
\text { sehingga anda bisa melihat transparansi } \\
\text { perkembangan BUMDes. }\end{array}$ & 0.06 & 4.0 & 0.23 \\
\hline 3. & $\begin{array}{l}\text { BUMDes BIMA mempromosikan usaha dan } \\
\text { kegiatan masyarakat melalui website/internet. }\end{array}$ & 0.09 & 4.1 & 0.38 \\
\hline 4. & $\begin{array}{l}\text { Anda merasa dimudahkan dengan adanya } \\
\text { website yang dibuat oleh BUMDes BIMA. }\end{array}$ & 0.10 & 4.1 & 0.40 \\
\hline 5. & $\begin{array}{l}\text { BUMDes BIMA mengembangkan usaha di } \\
\text { beberapa bidang seperti simpan pinjam, } \\
\text { pengelolaan sampah, sehingga memperoleh } \\
\text { laba. }\end{array}$ & 0.17 & 4.3 & 0.71 \\
\hline 6. & $\begin{array}{l}\text { BUMDes } \quad \text { BIMA } \\
\text { kegiatan ekonomi desa } \\
\text { dan transparan. }\end{array}$ & 0.13 & 4.4 & 0.55 \\
\hline 7. & $\begin{array}{l}\text { Masyarakat mengetahui laporan rutin perbulan } \\
\text { yang ada diakses melalui internet atau media } \\
\text { informasi. }\end{array}$ & 0.10 & 4.3 & 0.43 \\
\hline 8. & $\begin{array}{l}\text { Dalam kegiatannya untuk mencari keuntungan, } \\
\text { BUMDes BIMA juga memberikan manfaat } \\
\text { sosial untuk meningkatkan kesejahteraan } \\
\text { masyarakat seperti, memberikan lapangan } \\
\text { pekerjaan dan modal usaha untuk meningkatkan } \\
\text { pendapatan masyarakat di desa. }\end{array}$ & 0.12 & 4.5 & 0.54 \\
\hline 9. & $\begin{array}{l}\text { Sebagian keuntungan yang diperoleh BUMDes } \\
\text { BIMA disumbangakan untuk kepentingan } \\
\text { masyarakat. }\end{array}$ & 0.13 & 4.3 & 0.55 \\
\hline \multicolumn{2}{|c|}{ Nilai Total } & 1.00 & & 4.29 \\
\hline \multicolumn{4}{|c|}{ TOTAL Opportunities + Result } & 8.33 \\
\hline
\end{tabular}

Sumber: Olahan Peneliti, 2021 
Berdasarkan total skor internal factor evaluation (IFE) dan eksternal factor evaluation (EFE), kemudian dibuat diagram cartesius analisis SOAR yang didapatkan dari matriks IFE dan EFE sebagai berikut:

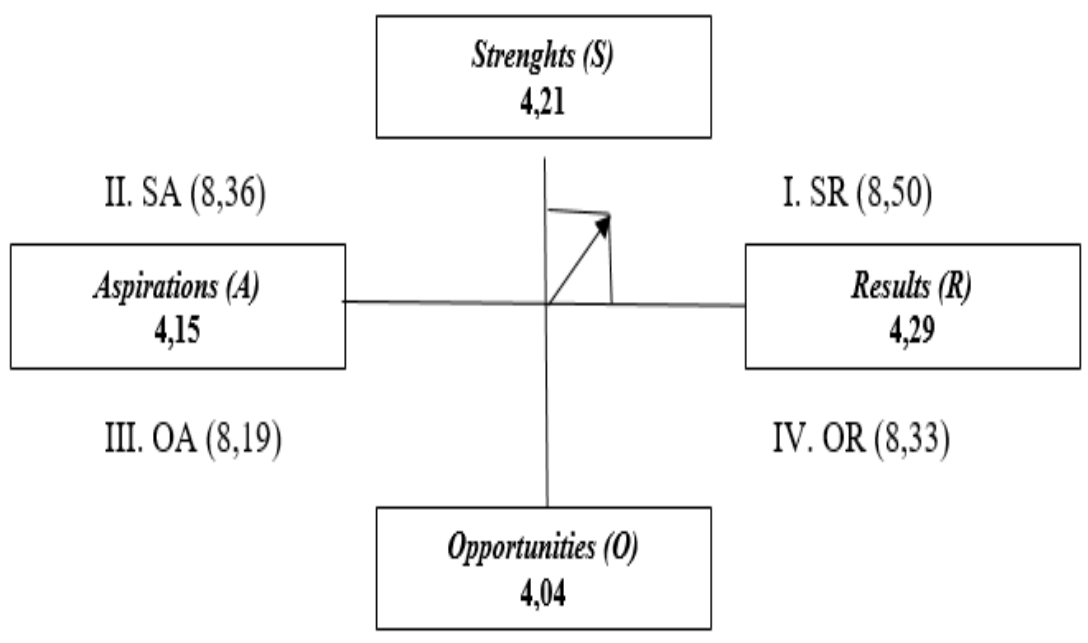

Sumber: Olahan Peneliti, 2021

\section{Gambar 1. Diagram Cartesius SOAR}

Total skor strength: 4,21

Total skor opportunities : 4,04

Total skor aspirations : 4,15

Total skor results : 4,29

Setelah didapatkan nilai total dari matriks IFE dan EFE yang digambarkan pada diagram cartesius SOAR, kemudian didapatkan hasil rumusan kombinasi strategi OS,OA, SR dan AR dari lingkungan internal dan eksternal pada Gambar 1. Kombinasi strategi matrik yang didapat dari indikator dan dilakukan penggabungan pada faktor internal dan eksternal, hasilnya bisa dilihat dari Tabel 5.

Tabel 5. Matriks Strategi Analisis SOAR BUMDes BIMA

\begin{tabular}{|c|c|c|}
\hline & Kekuatan (Strengths) & Aspirasi (Aspirations) \\
\hline IFAS & $\begin{array}{l}\text { 1. Mengutamakan fokus } \\
\text { manajemen pelayanan kepada } \\
\text { masyarakat. } \\
\text { 2. Pemanfaatan potensi kerajinan } \\
\text { tangan berupa sampah plastik } \\
\text { yang dapat dikelola menjadi } \\
\text { aksesoris rumah tangga. } \\
\text { 3. Mengadakan penyuluhan } \\
\text { berkala untuk para UMKM } \\
\text { mengenai kewirausahaan. } \\
\text { 4. Mempunyai program unit } \\
\text { unggulan yang selalu } \\
\text { dimanfaatkan oleh warga untuk } \\
\text { kepentingan bersama. }\end{array}$ & $\begin{array}{l}\text { 1. Mengharapkan regenerasi } \\
\text { kepengurusan } \\
\text { berjalan setiap tahunnya. } \\
\text { 2. Menjadikan BUMDes yang } \\
\text { sehat akan proses pengelolaan } \\
\text { dana desa. } \\
\text { 3. Memanfaatkan potensi desa } \\
\text { yang berada di lingkungan } \\
\text { industri. } \\
\text { 4. Meningkatkan keterampilan } \\
\text { masyarakat dalam bidang } \\
\text { kerajinan tangan. }\end{array}$ \\
\hline
\end{tabular}




\begin{tabular}{|c|c|c|}
\hline Peluang (Opportunities) & Strategi OS & Strategi OA \\
\hline 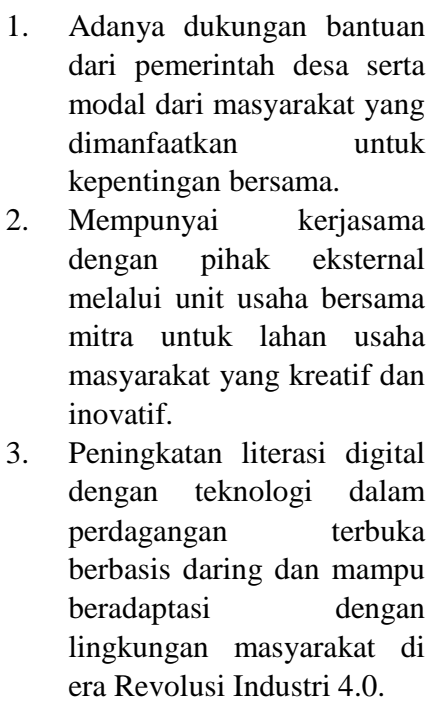 & $\begin{array}{l}\text { 1. Mengembangkan potensi } \\
\text { sumber daya alam dan sumber } \\
\text { daya manusia dengan membuat } \\
\text { penyuluhan secara berkala } \\
\text { dengan modal penyertaan dari } \\
\text { warga desa. } \\
\text { 2. Memfokuskan manajemen } \\
\text { pelayanan terhadap masyarakat } \\
\text { untuk mengembangkan } \\
\text { lingkungan di era Revolusi } \\
\text { Industri 4.0. }\end{array}$ & $\begin{array}{l}\text { 1. Modal penyertaan masyarakat } \\
\text { mampu meningkatkan } \\
\text { pengembangan keterampilan } \\
\text { masyarakat melalui penyuluhan } \\
\text { mengenai program kerja } \\
\text { BUMDes. } \\
\text { 2. Pemanfaatan wilayah BUMDes } \\
\text { BIMA yang berada di } \\
\text { lingkungan industri untuk } \\
\text { menjalin kerjasama lebih baik } \\
\text { agar mampu menghasilkan } \\
\text { tenaga kerja dan mengurangi } \\
\text { pengangguran desa. }\end{array}$ \\
\hline Hasil (Results) & Strategi SR & Strategi AR \\
\hline $\begin{array}{l}\text { 1. Menjadikan BUMDes } \\
\text { BIMA sebagai pilar } \\
\text { ekonomi masyarakat desa. } \\
\text { 2. BUMDes BIMA lebih bisa } \\
\text { memperhatikan masyarakat } \\
\text { yang kurang mampu yang } \\
\text { berada di desa. }\end{array}$ & $\begin{array}{l}\text { 1. Meningkatkan produktivitas } \\
\text { pelayanan manajemen } \\
\text { BUMDes BIMA untuk } \\
\text { masyarakat yang kurang } \\
\text { mampu. } \\
\text { 2. Pengurus BUMDes BIMA } \\
\text { harus lebih aktif dalam } \\
\text { mempromosikan kegiatan yang } \\
\text { berada di dalam BUMDes } \\
\text { melalui penyuluhan terhadap } \\
\text { warga dan juga melalui website } \\
\text { yang tersedia. }\end{array}$ & $\begin{array}{l}\text { 1. Merangkul warga sekitar untuk } \\
\text { lebih berperan aktif dalam } \\
\text { kegiatan BUMDes } \\
\text { 2. Mengupdate website BUMDes } \\
\text { mengenai pembaharuan yang } \\
\text { ada di dalam BUMDes agar } \\
\text { lebih transparan dan } \\
\text { memudahkan masyarakat untuk } \\
\text { mengakses. }\end{array}$ \\
\hline
\end{tabular}

Sumber: Olahan Peneliti, 2021

Berdasarkan Tabel 5 terkait analisis SOAR, Matriks IFAS dan EFAS yang hasilnya disajikan dalam diagram cartesius SOAR , hasil tersebut menunjukan posisi strategi yang perlu dilakukan oleh BUMDes BIMA yakni strategi SR. Strategi SR memuat 2 (dua) strategi ; strategi SR-1, Meningkatkan produktivitas pelayanan manajemen BUMDes BIMA untuk masyarakat yang kurang mampu. SR-2, Pengurus BUMDes BIMA harus lebih aktif dalam mempromosikan kegiatan yang berada di dalam BUMDes melalui penyuluhan terhadap warga dan juga melalui website yang tersedia.

\section{Kesimpulan}

Berdasarkan pembahasan dalam penelitian ini, peneliti menyimpulkan beberapa hasil penelitian sebagai berikut:

1. BUMDES BIMA memiliki empat kekuatan yakni, 1. Mengutamakan fokus manajemen pelayanan kepada masyarakat; 2 . Pemanfaatan potensi kerajinan tangan berupa sampah plastik yang dapat dikelola menjadi aksesoris rumah tangga; 3 . Mengadakan penyuluhan berkala untuk para UMKM mengenai kewirausahaan; 4. Mempunyai program unit unggulan yang selalu dimanfaatkan oleh warga untuk kepentingan bersama. BUMDes BIMA juga memiliki tiga peluang yakni, 1. Adanya dukungan bantuan dari pemerintah desa serta modal dari masyarakat yang dimanfaatkan untuk kepentingan bersama; 2 . Mempunyai kerjasama dengan pihak eksternal melalui unit usaha bersama mitra untuk lahan usaha masyarakat yang kreatif dan inovatif; 3. Peningkatan literasi digital dengan teknologi dalam perdagangan terbuka berbasis daring dan mampu beradaptasi dengan lingkungan masyarakat di era Revolusi Industri 4.0. Berdasarkan skor likert kekuatan 
yang paling dominan yakni pada skor 1,13 yaitu BUMDes BIMA sangat memperhatikan proses kesejahteraan masyarakat dengan diberlakukannya kegiatan simpan pinjam dan pengelolaan sampah yang menjadi produk unggulan untuk menghasilkan pundi-pundi rupiah untuk masyarakat desa yang berperan aktif didalamnya dan juga BUMDes BIMA menerima masukan dari masyarakat desa untuk kemajuan bersama. Sementara peluang paling besar yang dapat dimanfaatkan oleh BUMDes yakni skor paling tinggi terdapat pada 0,73 yaitu perkembangan usaha yang dijalankan masyarakat desa mampu untuk menambah pendapatannya, tidak terlepas dari strategi yang dijalankan oleh BUMDes BIMA dengan memberikan modal usaha pada masyarakat yang bisa memanfaatkan peluang usaha yang sudah ada.

2. BUMDES BIMA memiliki empat aspirasi yakni, 1. Mengharapkan regenerasi kepengurusan BUMDes berjalan setiap tahunnya; 2. Menjadikan BUMDes yang sehat akan proses pengelolaan dana desa; 3 . Memanfaatkan potensi desa yang berada di lingkungan industri; 4. Meningkatkan keterampilan masyarakat dalam bidang kerajinan tangan. BUMDes BIMA juga memiliki tiga hasil yakni, 1. Menjadikan BUMDes BIMA sebagai pilar ekonomi masyarakat desa; 2. BUMDes BIMA lebih bisa memperhatikan masyarakat yang kurang mampu yang berada di desa; 3 . Memiliki website untuk melihat transparansi kegiatan maupun keuangan BUMDes BIMA. Berdasarkan skor likert aspirasi yang paling dominan yakni pada skor 0,78 terkait usaha BUMDES yang dapat mensejahterakan masyarakat desa secara merata dengan cara Usaha simpan pinjam dan pengelolaan sampah yang dijalankan oleh BUMDes BIMA membantu perekonomian dan mensejahterakan masyarakat desa. sementara hasil/result skor 0.71 yang dimana BUMDes BIMA mampu mengembangkan usaha simpan pinjam dan pengelolaan sampah untuk mendapatkan laba yang bisa memberikan keuntungan untuk masyarakat dan mampu memperoleh kesejahteraan dalam bidang tersebut.

3. Berdasarkan diagram cartesius SOAR, strategi yang paling optimal untuk pemerataan ekonomi BUMDes BIMA yakni Strategi Strength-Result (SR). Dimana strategi ini menekankan pada 1. Meningkatkan produktivitas pelayanan manajemen BUMDes BIMA untuk masyarakat yang kurang mampu; 2. Pengurus BUMDes BIMA harus lebih aktif dalam mempromosikan kegiatan yang berada di dalam BUMDes melalui penyuluhan terhadap warga dan juga melalui website yang tersedia.

\section{Acknowledge}

Penulis menyadari bahwa skripsi ini masih banyak kekurang dan tidak mungkin dapat selesai tanpa adanya bantuan, dukungan, nasihat dan bimbingan dari berbagai pihak selama penyusunan skripsi ini. Oleh karena itu pada kesempatan ini penulis ingin menyampaikan rasa terima kasih terutama kepada:

1. Keluarga tercinta Mama Yeni Astuti, Ayah Zaenal Muttaqin, Kakak pertama saya Adam Ramadhan, Kakak kedua saya Ferri Prabu Ramadhan, dan Adik saya Zaihanim Sekar Ningrum yang telah membantu dan memberi dukungan yang sangat luar biasa kepada penulis selama masa kuliah dan dalam proses penyusunan skripsi ini.

2. Prof. Dr. H. Edi Setiadi, S.H., M.H selaku Rektor Universitas Islam Bandung

3. Dr. Nunung Nurhayati, S.E., M.Si., selaku Dekan Fakultas Ekonomi dan Bisnis Universitas Islam Bandung.

4. Ibu Dr. Ima Amaliah, S.E.,M.Si selaku Ketua Prodi Ekonomi Pembangunan.

5. Ibu Ade Yunita Mafruhat, S.E., M.Soc.Sc selaku dosen pembimbing I dan selaku wali dosen saya yang telah memberi motivasi serta membantu merealisasikan keinginan penulis dengan sabar memberikan arahan, referensi, koreksi, motivasi, dan apresiasi hingga skripsi ini dapat diselesaikan.

6. Bapak Meidy Haviz, S.E., M.Si, selaku dosen pembimbing II yang telah memberi motivasi serta membantu merealisasikan keinginan penulis dengan sabar memberikan arahan, referensi, koreksi, motivasi, dan apresiasi hingga skripsi ini dapat diselesaikan.

7. Seluruh Dosen Program Studi Ekonomi Pembangunan FEB UNISBA Prof. Dr. Atih Rohaeti Dariah, S.E., M.Si; Dr. Nurfahmiyati, S.E., M.Si; Dr. Asnita Frida Sebayang, 
S.E., M.Si; Meidy Haviz, S.E., M.Si; Noviani, S.E., M.Si; Dr. Dewi Rahmi, S.E., M.Si; Westy Riani, S.E., M.Sy; Yuhka Sundaya, S.E., M.Si; Aan Julia, S.E., M.Si.

8. Pihak dari Desa Margaasih dan BUMDes Bina Margaasih yang telah membantu dan memberikan dukungan penulis selama penyelesaian skripsi.

9. Akhir kata saya ucapkan Semoga amal baik semua pihak yang diberikan kepada penulis mendapatkan balasan dari Allah Subhanahu Wa Ta'ala. Akhir kata penulis mengucap syukur semoga tugas akhir skripsi ini dapat memberikan manfaat bagi kita semua.

\section{Daftar Pustaka}

[1] Adawiyah, R. (2018). Strategi Pengembangan Badan Usaha Milik Desa (Bumdes) Berbasis Aspek Modal Sosial (Studi Pada Bumdes Surya Sejahtera, Desa Kedungturi, Kecamatan Taman, Kabupaten Sidoarjo).

[2] Arianti, Firie, A, Y, E; Darwanto, Kushartono, W, E. 2016. Pengembangan Desa Mandiri Melalui Pengelolaan Badan Usaha Milik Desa (BUMDes). JDEB. Volume 13 (1) : 67 - 81.

[3] Anggraeni, S, R. 2016. Peranan Badan Usaha Milik Desa (Bumdes) Pada Kesejahteraan Masyarakat Pedesaan Studi Pada Bumdes Di Gunung Kidul, Yogyakarta. Jurnal MODUS. Volume 28 (2) : 155 - 167.

[4] Badan Usaha Milik Des. (2019). LPJ BUMDes BIMA. Kabupaten Bandung, BUMDes BIMA.

[5] BUMDes Bina Margaasih. 2020. Profil BUMDes Bina Margaasih (BIMA).

[6] Chintary, Q, dkk. 2016. Peran Pemerintah Desa Dalam Mengelola Badan Usaha Milik Desa (BUMDes). Jurnal Ilmu Sosial dan Ilmu Politik. Volume 5 (2) : 59 - 63.

[7] Desa Margaasih. 2020. Profil Desa Margaasih Kabupaten Bandung, Jawa Barat.

[8] Fahmi, A, R, dkk. 2018. Analisis pelaksanaan program social enterprise di bumdes nglanggeran. Jurnal working paper keuangan public islam. Volume 5 (1) : $1-10$.

[9] Ferdianto, Benny. 2016. Eksistensi Badan Usaha Milik Desa terhadap Peningkatan Pendapatan Asli Desa di Tiyuh Candra Kencana Kecamatan Tulang Bawang Tengah Kabupaten Tulang Bawang Barat. Lampung: Program Sarjana Fakultas Hukum Universitas Lampung.

[10] Fitriyanti, Siska. 2019. Analisis Potensi Pembentukan Badan Usaha Milik Desa (Bumdes) Berbasis Kearifan Lokal Di Desa Hiyung Kabupaten Tapin. Jurnal Kebijakan Pembangunan. Volume 14 (1) : 55 - 62.

[11] Kementerian Desa Pembangunan Daerah Tertinggal dan Transmigrasi, 2020. Indeks Desa Membangun 2020. Retrieved 2020, from idm.kemendesa.go.id.

[12] Kementerian Desa Pembangunan Daerah Tertinggal dan Transmigrasi, 2020. Indeks Desa Membangun 2019. Retrieved 2020, from idm.kemendesa.go.id.

[13] Kementerian Desa Pembangunan Daerah Tertinggal dan Transmigrasi. (2020). Indeks Desa Membangun Tahun 2019. Jakarta Selatan: Kementerian Desa, Pembangunan Daerah Tertinggal dan Transmigrasi.

[14] Kementerian Desa Pembangunan Daerah Tertinggal dan Transmigrasi. (2020). Indeks Desa Membangun Tahun 2020. Jakarta Selatan: Kementerian Desa, Pembangunan Daerah Tertinggal dan Transmigrasi.

[15] Meitriana, A, M, dkk. 2019. Peran badan usaha milik desa (BUMDes) dalam peningkatan kesejahteraan anggota ditinjau melalui kewirausahaan sosial. Jurnal Pendidikan Ekonomi. Volume 11 (2) : $498-508$

[16] Republik Indonesia. 2014. Undang-Undang No.6 Tahun 2014 Tentang Desa. Lembaran Negara RI Tahun 2014, No.18. Sekretariat Negara. Jakarta

[17] Republik Indonesia. 2004. Undang-Undang No.32 Tahun 2004 Tentang Pemerintahan Daerah. Tambahan Lembaran Negara RI No.4437. Sekretariat Negara. Jakarta.

[18] Pemerintah Desa Margaasih Kabupaten Bandung. (2020). RPJM DESA Margaasih 20192025. Kabupaten Bandung: Pemerintah Desa Margaasih. 
[19] Peraturan Menteri dalam negeri nomor 39 Tahun 2010 tentang Badan Usaha Milik Desa (BUMDES).

[20] Prasetyo,R,A. 2016. Peranan Bumdes Dalam Pembangunan Dan Pemberdayaan Masyarakat Di Desa Pejambon Kecamatan Sumberrejo Kabupaten Bojonegoro. Jurnal Dialektika. Volume XI (1) : 86 - 100 .

[21] Rahman, Arif, Mohd. 2019. Studi Evaluasi Kinerja Bidang Usaha Badan Usaha Milik Desa (Bumdes) Muara Uwai Sejahtera Desa Muara Uwai Kecamatan Bangkinang Kabupaten Kampar Tahun 2017. JOM FISIP. Volume 6 (1) : 1 - 16.

[22] Solekhan, 2012. Strategi Pengembangan Badan Usaha Milik Desa dalam Meningkatkan Kesejahteraan Masyarakat Desa di Desa Lancang Kuning Kecamatan Bintan Utara. Naskah Publikasi, (130563201023), 1-21.

[23] Samsir, Andi. 2016. Studi Komparatif Model BUMDes di Kabupaten Bantaeng. Jurnal Administrare. Volume 3 (2) : $46-58$.

[24] Widiastuti, Yumia. 2019. Pengaruh Faktor Sosial Ekonomi Petani Kopi Dengan Kinerja Bumdes Di Dusun Sumberdadi Desa Kandangan, Kecamatan Pesanggaran, Kabupaten Banyuwangi. Jurnal Agrisains. Volume 3 (1) : 1 - 5 